\title{
Geohazards in Subduction Zone Environments and their Implications for Science and Society
}

\section{Preface}

\author{
Guest Editors \\ Yujiro Ogawa ${ }^{1}$, Yildirim Dilek ${ }^{2}$ and ShinjI TaKarada ${ }^{3}$ \\ ${ }^{1}$ University of Tsukuba, Japan. E-mail: fyogawa45@yahoo.co.jp \\ ${ }^{2}$ Miami University, USA.E-mail: dileky@miamioh.edu \\ ${ }^{3}$ Geological Survey of Japan, AIST, Japan. E-mail: s-takarada@aist.go.jp
}

\begin{abstract}
A joint meeting of the 2nd G-EVER (Asia-Pacific Region Global Earthquake and Volcanic Eruption Risk Management) International Symposium and the 1st IUGS (International Union of Geological Sciences) \& SCJ (Science Council of Japan) International Workshop on Natural Hazards was held on October 19-20, 2013, in Sendai, Japan. The workshop also included a field trip on October 21 (please refer to the article by E. Tsukuda in this issue for details). The aim of the joint meeting and workshop was to examine the most recent observations and data from seismically active subduction zone environments and to discuss the most effective methods in order to reduce the risks from natural disasters such as earthquakes, tsunamis, landslides, and volcanic eruptions, particularly in and around active subduction zones. The workshop was well attended, with 94 participants representing 12 countries, and thirty national and international institutes contributed to and produced the content of the "Sendai Agreement". The agreement was unanimously endorsed by all participants (please refer to the article by E. Tsukuda for details).
\end{abstract}

There were 55 papers presented during the workshop, followed by intensive and thematic discussions on the scientific and societal implications of the exchanged data, observations, and results. The organizers and the participants also considered the relevant outstanding questions and problems regarding various natural hazards, the level of preparedness of different societies and nations for such hazards and potential future workshops to better understand the mode of natural hazards and the related societal and governmental issues. This special issue of Episodes is one of the manifestations of this workshop in Sendai and contains thirteen of the papers presented at the workshop.

The Sendai joint meeting and workshop were planned after the devastating earthquake and tsunami of the March 2011 Tohoku-oki Earthquake $(\mathrm{Mw}=9.0)$ in this region. The large magnitude earthquake was a result of slip on a subduction-type low-angle thrust fault along the Japan Trench. The Japanese word "oki" means offshore, while "Tohoku" refers to the regional name of Northeast Honshu, Japan, where the city of Sendai is located. The major property damage and the fatalities associated with the Tohoku-oki disaster were caused almost entirely by the tsunami, which occurred immediately after the earthquake. Rapid tsunami flooding (inundation) along the shorelines of northeastern Japan and deep into the land along some of the river systems resulted in more than 18,000 fatalities, including numerous missing people. The aftershock of this double disaster was enormous for the usually very resilient Japanese nation, and showed to the world that even one of the most physically and emotionally well prepared society for such disasters needed more sophisticated, long-term planning for effective forecasting, rapid evacuation, efficient mitigation, and government response than before.

The Fukushima Daiichi ("Daiichi” means No. 1) nuclear power plant in the towns of Okuma and Futaba in the Fukushima Prefecture was also damaged extensively by the tsunami flood and the loss of electric power after the events took place. Subsequent radioactive leakage from the storage units caused some level of contamination of the soil and water nearby, creating further concerns and problems for the local people and government. Such large-scale, subductiontype earthquakes ( $\geq$ Mw 9.0) occurred previously in Chile (1960), Alaska (1964), and Sumatra (2004). However, an earthquake of such magnitude was not anticipated near the Japan Trench, although some observations and discussions on its potential were made by geophysicists, geologists, and geomorphologists in the past. Just after the earthquake and the ensuing tsunamic event, numerous scientific papers were edited, published, and presented at scientific meetings in a short period of time. However, the societal aspects and the ramifications of these kinds of natural geohazards for the welfare of nations and societies received less attention in the publication media and were thus significantly underscored.

Subduction zones, where one lithospheric plate dives under another one, are also known for other types of natural hazards associated with volcanism, earthquake-induced landslides, and coastal flooding-erosion. The nature of these geohazards is relatively well 
understood in recent years as a result of technologically driven fundamental and frontier research, linking such events to dynamic processes on Earth. Less accomplished over the years, in comparison, is the efficiency of transferring all this scientific knowledge to policymaking and societal understanding of the real causes of such disasters and to the development of early warning systems and risk assessment and reduction plans and strategies. This goal requires collective and collaborative efforts, and skills of earth scientists, engineers, socioeconomists, health organizations and governmental policy-makers at regional and global scales. Increasingly, responding to the consequences of geohazard events has become the responsibility of international scientific unions and intergovernmental organizations. Therefore, we also need to better learn and practice how to disseminate and transfer the learned knowledge, science and data in a transdisciplinary fashion, while avoiding the technical jargon in communicating with the governmental bodies, policy-makers, and people.

This special issue of Episodes is intended to serve this purpose. The papers herein focus on the nature of crustal movements, seismic events, paleo-tsunamological and tsunami-modeling studies, and landslides particularly in Asia and the Pacific Rim, along the trench systems of Japan (from the Japan Trench to the Ryukyu Trench, through the Sagami and Nankai Troughs), the Russian and Chinese continental margins. The subduction zone and continental margin geohazards studies include potential risk assessment and management plans. Some effective strategic and ethical issues are also presented in this issue.

World leaders (and policy-makers) often have an impression that geohazards and natural disasters as very serious but rather rare events. We hope that the new generation of leaders shall express more concern on the enormous potential risks to their people brought about by the occurrence of geohazards and related disasters in the future.

We gratefully acknowledge all the people who participated in the preparation of the Sendai joint meeting and workshop, particularly the G-EVER Consortium Promotion Team, AIST international management division, Tohoku University researchers, International Research Institute of Disaster Science (IRIDeS) of the Tohoku University, IUGS, SCJ, and the IUGS Branch of Earth and Planetary Science Board of SCJ, for their financial and spiritual support. We also express our sincere thanks to the authors for their valuable contributions to this special issue and to the reviewers for their constructive and timely comments on the manuscripts. Finally, we would like to thank the IUGS Executive Committee for helping us materialize this special issue, and Dr. Brian Marker and Dr. Fareed Fareeduddin, in charge of the publication of Episodes, for their help, encouragement and editorial processing of the papers for publication in the special issue. 